\title{
Tensile Bond Strength of Different Adhesive Systems to Enamel and Dentin
}

\author{
Wanessa Christine SOUZA-ZARONI \\ Letícia Caliento SEIXAS \\ Juliane Cristina CICCONE-NOGUEIRA \\ Daniela Thomazatti CHIMELLO \\ Regina Guenka PALMA-DIBB \\ Department of Restorative Dentistry, School of Dentistry of Ribeirão Preto, \\ University of São Paulo, Ribeirão Preto, SP, Brazil
}

\begin{abstract}
The aim of this study was to assess the tensile bond strength of four adhesive systems to enamel and dentin: Clearfil Liner Bond 2V C, Prime\&Bond NT/NRC - PB, Single Bond - SB and All Bond 2 -AB. For such purpose, 40 sound human molars were selected. Crowns were bisected in a mesiodistal direction and each half was ground until flat enamel (E) or dentin (D) surfaces were obtained. A total of 80 specimens were randomly assigned to 4 groups ( $n=20,10$ in enamel and 10 in dentin). After surface treatment, a composite resin (Z250; 3M) cone was prepared using a split Teflon ${ }^{\circledR}$ matrix. Bond strength was tested in an universal testing machine (0.5 mm/ min). Bond strength means in MPa were: C - E: 18.66 ( \pm 2.67$)$ and D: 21.62 ( \pm 5.29$)$; PB - E: 18.13 ( \pm 2.96$)$ and D: 3.19 ( \pm 1.40$)$; SB E: 20.06 ( \pm 6.11$)$ and D: $16.95( \pm 2.57)$; AB - E: $18.20( \pm 3.94)$ and D: $15.94( \pm 4.72)$. Statistical analysis of data by two-way ANOVA showed that $\mathrm{C}$ presented the best results followed by SB. In conclusion, among the tested materials, Clearfil Liner Bond 2V self-etching primer adhesive syetem had the best performance. The substrate type influenced bond strength, being higher to enamel.
\end{abstract}

Key Words: bond strength, enamel, dentin, adhesive systems.

\section{INTRODUCTION}

In composite restorations, stable adhesion to the tooth is essential for clinical success. Recently, many adhesive systems, such as wet-bonding and self-etching primer systems have been launched to market.

In great part of currently available adhesive systems the primer and bonding agent are combined in a single bottle, in an attempt to reduce the number of steps and make these products more practical than the multiple-bottle bonding agents (1). Although commonly marketed as "one-step" systems, indeed most of them require a separate acid conditioning/rinsing step and the application of several coats of primer/adhesive.

Recent developments in dentin bonding have reintroduced the concept of utilizing the smear layer as a bonding substrate, but with novel insights and improved formulations that can etch beyond the smear layer into the underlying dentin matrix (2). This promising approach to dentin adhesion involves the use of acidic primers, which combine the acid etching and priming steps. The goal of the so-called self-etching primers adhesive systems was to simplify the bonding procedure and to reduce the sensitivity technique of the adhesive protocol by eliminating the acid conditioning step (3). Although the most reliable conclusions on the performance of bonding systems in the mouth must be derived from long-term clinical trials, laboratory assays are still useful to compare their bonding performance and the most common method to evaluate adhesive properties of restorative materials is bond strength assessment.

Given the great variability in formulation, characteristics and acting mode of commercially available bonding agents, it is of interest to establish the most

Correspondence: Profa. Dra. Regina Guenka Palma Dibb, Faculdade de Odontologia de Ribeirão Preto,USP, Departamento de Odontologia Restauradora, Avenida do Café, S/N, 14040-904 Ribeirão Preto, SP, Brasil. Tel: +55-16-3602-4016. Fax:+55-16-3633-0999. e-mail: rgpalma@forp.usp.br 
appropriate bonding protocol. This study assessed the bond strength of different adhesive systems (multibottle, one-bottle and self-etching primer systems) to enamel and dentin.

\section{MATERIAL AND METHODS}

Forty sound human molars, extracted within a six-month period and stored in thymolized saline at $4^{\circ} \mathrm{C}$, were selected and cleaned with scaler and rubber cup pumice prophylaxis. Roots were sectioned $2 \mathrm{~mm}$ below the cementoenamel junction and crowns were bisected longitudinally in a mesiodistal direction with a watercooled diamond saw in a sectioning machine, providing a total of 80 halves. Surfaces were identified to avoid both buccal and lingual halves of the tooth being assigned to the same experimental group. Then, halves were individually embedded in acrylic resin using PVC cylinders (2.1 cm diameter; $1.1 \mathrm{~cm}$ height) and ground using \#120-600 sandpapers until flat enamel (E) or dentin (D) surfaces were obtained.

Specimens were randomly assigned to 4 groups of equal size, according to the adhesive system used: Clearfil Liner Bond 2V (C); Prime\&Bond NT/NRC
(PB); Single Bond (SB) and All Bond 2 (AB). The tested materials with their compositions, specifications and manufacturers are given on Table 1. Each main group was divided into two subgroups $(\mathrm{n}=10)$, according to the substrate, enamel (E) or dentin (D).

The tooth surfaces were treated and the adhesives were applied to a delimited surface area of the enamel or dentin, according to each manufacturer's instructions.

For the first group (E and D), Clearfil Liner Bond $2 \mathrm{~V}$ self-etching primer adhesive system was used. Equal drops of primer liquids A and B were dispensed into a well of the mixing dish and mixed immediately before application. The resultant mixture was applied to the entire surface with a disposable brush tip, left undisturbed for $30 \mathrm{~s}$ and gently air-dried to evaporate the volatile ingredients. No rinsing was accomplished. Then, Bond liquid A was applied to the entire dental substrate, slightly thinned with a mild oil-free air stream and lightcured for $20 \mathrm{~s}$, with a visible light curing-unit with a 450 $\mathrm{mW} / \mathrm{cm}^{2}$ output. The second group (E and D) was bonded with Prime\&Bond NT/NRC, also a self-etching primer adhesive. NRC mixture was applied and left undisturbed for $20 \mathrm{~s}$. The excess was removed with air spray and NT was applied, left undisturbed for $20 \mathrm{~s}$ and

Table 1. Tested adhesive systems.

\begin{tabular}{|c|c|c|c|}
\hline Material & Etchant/ Self-etching primer & Adhesive & Manufacturer \\
\hline $\begin{array}{l}\text { Clearfil } \\
\text { Liner Bond 2V }\end{array}$ & $\begin{array}{c}\text { Primer A: MDP, } \\
\text { HEMA, water, photoinitiator, } \\
\text { accelerator; Primer } B \text { : } \\
\text { HEMA, water, accelerator }\end{array}$ & $\begin{array}{c}\text { MDP, dimethacrylates } \\
\text { photoinitiator, accelerator; } \\
\text { microfiller }\end{array}$ & $\begin{array}{l}\text { Kuraray Co } \\
\text { Osaka, Japan }\end{array}$ \\
\hline
\end{tabular}

Prime\&Bond NT/NRC

Single Bond
35\% phosphoric acid

NRC: maleic acid, itaconic acid, water

35\% phosphoric acid
PENTA, UDMA, Resin R5-62-1, T-resin,nanofiller, initiators, stabilizer, cetylaminehydrofluoride, acetone

Bis-GMA, HEMA, water, polyalkenoic acid copolymer, ethanol, dimethacrylates

Primer A: NTG-GMA, acetone, water, ethanol; Primer B: BPDM, $\mathrm{CQ}$, acetone, ethanol; Bond: BisGMA, HEMA, amine activator, CQ
Dentsply De Trey, Kontanz, Germany

3M Dental Products St Paul, MN, USA

Bisco Inc, Itasca, IL, USA 
gently air-dried to evaporate the volatile ingredients for $5 \mathrm{~s}$, then light-cured for $10 \mathrm{~s}$. The third group used an ethanol-based, single-bottle bonding agent, Single Bond. Tooth surface was etched with a 35\% phosphoric acid gel for $15 \mathrm{~s}$, rinsed for $10 \mathrm{~s}$ and gently dried with a cotton pellet to remove water excess and keep the tooth surface moist. Bonding agent was applied using a small brush, dried with a gentle stream of air for $5 \mathrm{~s}$ and light-cured for $10 \mathrm{~s}$. For the last group, the adhesive protocol was accomplished using All Bond 2, a multiple-bottle system. The tooth surface was etched with a 35\% phosphoric acid gel for $15 \mathrm{~s}$, rinsed for $10 \mathrm{~s}$ and gently dried with a cotton pellet to remove water excess and keep tooth surface moist. Equal drops of primer liquids A and B were dispensed into a well of the mixing dish and mixed immediately before application. The resultant mixture was applied to the entire substrate with a disposable brush tip for five times, and gently air-dried. Then, bond liquid was applied to the entire surface, slightly thinned with a mild oil-free air stream and light-cured for $20 \mathrm{~s}$.

After bonding, each specimen was fixed in a metallic clamping device (developed by The Houston Biomaterial Research Center) keeping the demarcated site parallel to a flat surface. A split bisected Teflon ${ }^{\circledR}$ matrix was positioned over the tooth/resin block resulting in an inverted conical cavity with the smaller diameter coincident to the delimited bonding area $(\varnothing 3 \mathrm{~mm})$.

A hybrid light-cured composite resin (Filtek Z250) was inserted into the matrix in three increments, polymerized for $40 \mathrm{~s}$ each. As the matrix cavity was completely filled, the specimen was removed from the clamping device and the matrix was opened and separated, leaving adhered to the limited dentin surface an inverted, composite resin cone with a diameter of $6 \mathrm{~mm}$ tapering to a diameter of $3 \mathrm{~mm}$ and $4 \mathrm{~mm}$ high.

After 24 -hour storage in distilled water at $37^{\circ} \mathrm{C}$, each cone-shaped composite/acrylic resin blocks placed into an apparatus with an internal taper corresponding to the specimen shape. This configuration was loaded in tension in an universal testing machine at a crosshead speed of $0.5 \mathrm{~mm} / \mathrm{min}$ and $50 \mathrm{kgf}$ load cell until fracture. Bond strength means (in MPa) and standard deviation were determined and analyzed statistically by two-way ANOVA and Tukey's test at 5\% significance level.

The debonded enamel and dentin sites were viewed under a stereoscopic magnifier (40x) to assess the failure mode. Adhesive failure was considered to be the one at the specimen/adhesive interface; cohesive failure occurred in the material or substrate, with no damage to the interface; mixed failure was the one involving at the same time the interface and the material.

\section{RESULTS}

Bond strength means and standard deviation are givenin Table 2. Bond strength to enamel was higher than to dentin independently of adhesive system.

Clearfil Liner Bond 2V presented statistically significant higher bond strength than the other materials $(\mathrm{p}<0.05)$. The lowest bond strength means, especially to dentin, was obtained for Prime\&Bond, which differed significantly to the other adhesive systems $(\mathrm{p}<0.05)$. In the adhesive system $x$ substrate interaction, all materials had similar results in enamel and differed in dentin, Clearfil Liner Bond 2V, presenting the best result.

Failure after testing mostly occurred involving at the same time the bonding interface and the adhesive system/composite resin (mixed failure) or only the adhesive interface (adhesive failure), except for Clearfil Liner Bond $2 \mathrm{~V}$ in dentin, which showed mixed or cohesive failures in composite for most specimens.

\section{DISCUSSION}

In this study, no difference in bond strength to enamel was found among total-etch adhesive systems, wet-bonding and self-etching primer adhesive systems. These results are in accordance with those of previous studies (4-6), which also found no significant difference in bond strength to ground enamel conditioned by phosphoric acid and self-etching primer. However, it has been reported $(3,7,8)$ that there is a great difference in the morphology of enamel treated with phosphoric acid versus self-etching primer when observed under scanning electron microscopy. Phosphoric acid etching

Table 2. Bond strength means and standard deviations.

\begin{tabular}{llc}
\hline Material & \multicolumn{1}{c}{ Enamel } & Dentin \\
\hline Clearfil Liner Bond 2V & $18.66 \pm 2.27 \mathrm{bc}$ & $21.62 \pm 5.29 \mathrm{a}$ \\
Prime\&Bond NT/NRC & $18.13 \pm 2.96 \mathrm{bcd}$ & $3.19 \pm 1.04 \mathrm{e}$ \\
Single Bond & $20.06 \pm 6.11 \mathrm{ab}$ & $16.95 \pm 2.57 \mathrm{~cd}$ \\
All Bond 2 & $18.20 \pm 3.94 \mathrm{bcd}$ & $15.94 \pm 4.72 \mathrm{~d}$ \\
\hline
\end{tabular}

Different letters indicate statistically significant difference at 5\%. 
creates a deep etching pattern on enamel surface, with thick tag-like extensions, while self-etching primer selectively decalcifies the interprismatic enamel, presenting thin tag-like extensions $(3,4)$.

The concept of infiltrating the hydrated demineralized dentin matrix with a hydrophilic resin capable of interweaving with the exposed collagen network has been supported by several studies as being the principle to achieve appropriate dentin bonding. Acid etching opens and widens the orifices of dentinal tubules, increases intratubular dentin exposure/permeability and demineralizes intertubular dentin, reportedly to a depth of 7 micrometers (9). The subsequent infiltration and polymerization of the monomer results in a resin-dentin inter-diffusion zone or hybrid layer, which is the source of bonding to acid-etched dentin $(1,10,11)$.

It has been shown that the depth of the demineralized intact dentin relates to the concentration of the acidic monomer in the primer and the application time of primer (11). The overall acidity of a primer mixture will determine its self-etching potential (12). A minimum $\mathrm{pH}$ value would be required for any primer solution to counteract the buffering capacity of the smear layer and intact dentin before it can etch beyond those substrates. One of the self-etching primer systems tested in this study, Clearfil Liner Bond 2V, has in its composition MDP, an acidic phosphate resin monomer that replaced the phenyl-P from the original formulation (2). The primer acidity $(2.8 \mathrm{pH})$, although less than that of $32-37 \%$ phosphoric acid gels is sufficient to etch through the smear layer into the underlying dentin.

That improved etching potential of nonrinsed, self-etching primers coupled to the application of a polymerizable adhesive layer forms a thin hybridized complex, comprising an upper and a lower portion. The upper portion is the result of resin infiltration into the demineralized smear layer, the so-called hybridized smear layer. The lower, thinner portion is due to the formation of a true hybrid layer through the interweaving the of resin monomer with the collagen web within the demineralized dentin matrix. The only material connecting these two layers is the diffused resin. Although the hybridized complex is usually thinner than the hybrid layer formed by adhesive agents using phosphoric acid etching (generally less than 2-micrometer-thick) it has been shown that self-etching primers produce relatively high bond strength to dentin $(13,14)$.

The findings of a previous investigation (2) with a self-etching primer (Clearfil SE Bond) showed that the thickness of the underlying true hybrid layer remained reasonably consistent (ca 400 to $500 \mathrm{~nm}$ ), despite great variation in thickness of the surface hybridized smear layer (0 to 4.1 micrometers). This thin layer is possibly mainly responsible for the high bond strength produced by this adhesive system, which may indicate that hybrid layers do not have to be thick to be strong, as long as the collagen fibrils are optimally infiltrated by resin. No correlation between hybrid layer thickness/morphology and bond strength could be found $(15,16)$.

In the present study, the self-etching systems showed different bond strength to dentin, i.e., Clearfil had higher means than Prime\&Bond NT/NRC. On the other hand, there was no difference between Clearfil and Single Bond total-etch system in enamel. Another work (17) found higher bond strength to dentin with Prime\&Bond NT/NRC than that of the present study, as well as similar bond strength for Prime\&Bond NT/NRC and Single Bond, and similar incidence of adhesive failures for both systems. In the present study, most tested systems showed a large number of mixed failures in enamel and cohesive in dentin, except for All Bond 2, which showed adhesive failures in both substrates, as published elsewhere (18).

A suitable explanation for the better performance of Clearfil Liner Bond 2V would be that self-etching primers are generally less technique-sensitive than totoaletch bonding agents because the acidic monomer of self-etching systems demineralizes superficially dentin surface by partially dissolving mineral crystals around the collagen fibrils and simultaneously permitting monomer infiltration, as the demineralizing component of the primer is also the infiltrating resin $(1,2)$. Because the tooth surface is not rinsed following treatment with acidic primers, there is no loss of dentin mass. This is thought to minimize the susceptibility to shrinkage or collapse of the collagen network (10), thereby providing optimal bonding. On the other hand, the poor performance of Prime\&Bond NT/NRC system in dentin is probably related to the use of maleic acid as a component of the self-priming. It was observed (19) that when applying weak acids (maleic acid or Na-EDTA) to dentin for 15 $\mathrm{s}$, bond strength significantly decreased compared to 60 -s applications, given that the highest bond strength was obtained with application of maleic acid for $60 \mathrm{~s}$, or phosphoric acid for $15 \mathrm{~s}$.

Additionally, adhesive systems with water-based 
primers seem less critical as far as the wetness of the acid-conditioned dentin is concerned (20). Adhesive systems with ethanol- or acetone-based primers show a restricted "windows of opportunity" since a precise amount of water should be retained post-conditionally on dentin surface for efficient bonding to be achieved (20). Depending on the water content of the primer system, different sensitivity ranges or shifts in the "windows" for optimal adhesion have been observed. Differences in the bond strength of the tested systems may be a result of different primer formulations.

Current developments in dentin bonding have focused on simplifying the application methods by decreasing the time and steps required for placement. While these simplified adhesive systems are convenient, some of them had their efficacy for stable bonding already demonstrated. Although, long-term clinical trials are needed to fully understand the performance of the newly developed bonding systems.

\section{RESUMO}

Este estudo avaliou a resistência à tração de diferentes sistemas adesivos ao esmalte/dentina: Clearfil Liner Bond 2V - C, Prime\&Bond NT/NRC - PB, Single Bond -SB and All Bond 2 AB. Quarenta molares humanos hígidos tiveram suas coroas seccionadas no sentido mesio-lingual, e posteriormente lixadas até que fossem obtidas superfícies lisas de esmalte (E) ou dentina (D). Oitenta espécimes foi aleatoriamente dividido em 4 grupos $(n=20,10$ em esmalte e 10 em dentina). Após o tratamento da superfície de acordo com cada sistema adesivo testado, um cone de resina composta Z250 (3M) foi preparado com uma matriz de Teflon ${ }^{\circledR}$. O teste de tração foi realizado em uma máquina universal de ensaios $(0.5 \mathrm{~mm} / \mathrm{min})$. As médias de resistência à tração (em MPa) foram: C - E: 18,66 ( $\pm 2,67)$ e D: $21,62( \pm 5,29)$; PB - E: $18,13( \pm 2,96)$ e D: $3,19( \pm 1,40)$; SB - E: 20,06 $( \pm 6,11)$ e D: 16,95 $( \pm 2,57) ; \mathrm{AB}-\mathrm{E}: 18,20( \pm 3,94)$ e D: $15,94( \pm 4,72)$. A análise estatística (ANOVA a critérios e teste de Tukey) mostrou que C obteve os melhores resultados, seguido por SB. Concluiu-se que, dentre os materiais testados, o Clearfil Liner Bond 2V teve melhor desempenho, e que o tipo de substrato tratado influenciou na resistência adesiva, sendo esta maior em esmalte.

\section{REFERENCES}

1. Van Meerbeek B, De Munck J, Yoshida Y, Inoue S, Vargas M, Vijay P, et al. Buonocore memorial lecture. Adhesion to enamel and dentin: current status and future challenges. Oper Dent 2003; 28:215-235.

2. Tay FR, Sano H, Carvalho R, Pashley E, Pashey D. An ultrastructural study of the influence of acidity of self-etching primers and smear layer thickness on bonding to intact dentin. J Adhes Dent 2000;2:83-98.

3. Perdigão J, Lopes L, Lambrechts P, Leitão J, Van Meerbeek
B, Vanherle G. Effect of a self-etching primer on enamel shear bond strengths and SEM morphology. Am J Dent 1997; 10:141-146.

4. Kanemura N, Sano H, Tagami J. Tensile bond strength and SEM evaluation of ground and intact enamel surface. J Dent 1999;27:523.

5. Torii Y, Itou K, Hisaka R, Iwata S, Nishitani Y. Enamel tensile bond strength and morphology of resin-enamel interface created by acid etching system with or without moisture and self-etching priming system. J Oral Rehabil 2002;29:528-533.

6. Shimada Y, Tagami J. Effects of regional enamel and prism orientation on resin bonding. Oper Dent. 2003; 28:20-27.

7. Miyazaki M, Iwazaki K, Onose H, Moore BK. Enamel and dentin bond strength of single application bonding systems. Am J Dent 2001;14:361-366.

8. Miranda MS, Cal Neto JOAP, Barceleiro MO, Dias KRHC. SEM evaluation of a non-rinse conditioner and a self-etching adhesive regarding enamel penetration. Oper Dent 2006; 31:78-83.

9. Van Meerbeek B, Inokoshi S, Braem M, Lambrechts P, Vanherle G. Morphological aspects of the resin-dentin interdiffusion zone with different dentin adhesive systems. J Dent Res 1992;71:1530-1540.

10. Nakabayashi N, Kojima K, Masuhara E. The production of adhesion by the infiltration of monomers into tooth substrates. J Biomed Mater Res 1982;16:265-273.

11. Ferrari M, Mannocci F, Vichi A, Davidson CL. Effect of two etching times on the sealing ability of Clearfil Liner Bond 2 in class V restorations. Am J Dent 1997;10:66-70.

12. De Munck J, Van Landuyt K, Peumans M, Poitevin A, Lambrechts P, Braem M, Van Meerbeek B. A critical review of the durability of adhesion to tooth tissue: Methods and results. J Dent Res 2005;84:118-132.

13. Pereira PNR, Okuda M, Sano H, Yoshikawa T, Burrow MF, Tagami J. Effect of intrinsic wetness and regional difference on dentin bond strength. Dent Mat 1999;15:46-53.

14. Yoshiyama M, Matsuo T, Ebisu S, Pashley D. Regional bond strengths of self-etching/self-priming adhesive systems. J Dent 1998;26:609-616.

15. Prati C, Chersoni S, Mongiorgi R, Pashley, DH. Resin infiltrated dentin layer formation of new bonding systems. Oper Dent 1998;23:185-194.

16. Uekusa S, Yamaguchi K, Miyazaki m, Tsubota K, Kurokawa $\mathrm{H}$, Hosoya Y. Bonding efficacy of single-step self-etch systems to sound primary and permanent tooth dentin. Oper Dent 2006; 31:569-576.

17. Burrow MF, Nopnakeepong, U, Phrukkanon S. A comparison of microtensile bond strength of several dentin bonding systems to primary and permanent dentin. Dent Mat 2002; 18:239-53.

18. Armstrong SR, Boyer DB, Keller JC. Microtensile bond strength testing and failure analysis of two dentin adhesives. Dent Mat 1998; 14:44-50.

19. Benderli Y, Yügel T. The effect of surface treatment on the bond strength of resin composite to dentin. Oper Dent 1999; 24:96-102.

20. Perdigão J, Lambrechts P, Van Meerbeek B, Braem M, Yildiz E, Yucel T, Vanherle G. The interaction of adhesive systems with dentin. Am J Dent 1996;9:167-173.

Accepted February 4, 2004 